\title{
Experimental study of electric vehicle gearbox efficiency
}

\author{
Josef Břoušek ${ }^{1, *}$, and Tomáš Zvolský1 \\ ${ }^{1}$ Technical University of Liberec, Department of Vehicles and Engines, 46117 Liberec, Czech Republic
}

\begin{abstract}
This paper presents an experimental analysis of the overall efficiency of the gearbox for an electric vehicle with a Dual Motor Drive System (DMDS) propulsion system. The efficiency was measured in the powertrain testbed where the gearbox was placed between two dynamometers. The main aim of the experiment was to get relevant values of an overall efficiency as a function of input speed and torque. All these measured values of the gearbox efficiency are included in graphs and efficiency maps. Tests were run with two different amounts of oil charge. The experiment confirmed the expected high values of the overall mechanical gearbox efficiency. The results can be used further for advanced simulations and other electric vehicle experiments.
\end{abstract}

\section{Introduction}

Nowadays, researchers and automobile producers come together in search of a way to increase the efficiency of vehicles by perfecting or changing the technology and concepts incorporating the idea of modern transportation [1]. The whole world has been focused in recent years on vehicles with alternative vehicle propulsion such as electric (EV) and hybrid (HEV) vehicles because of emission restrictions and fuel consumption of vehicles related to global warming and limited energy resources. Research and development are focused on new drive concepts and systems that allow for greater availability of known technologies in terms of affordability and reliability of these drives [2]. The main topics in the field of $\mathrm{EV}$ are drive range extension per one charge, performance increase and drive efficiency [3].

The overall efficiency of the EV propulsion system is shown in Fig. 1 and described in formula (1). The overall efficiency $\eta_{E V}$ includes battery efficiency $\eta_{1}$, power converter and electric motor efficiency $\eta_{2}$ and gearbox efficiency $\eta_{3}$ [4]. $P_{1}$ is input power, $P_{2}$ is output power. $P_{\text {LOSS1 }}$ are losses in battery, $P_{\text {LOSS2 }}$ are losses in power converter and electric motor, $P_{\text {LOSS3 }}$ are losses in gearbox. If we want to focus on improving the overall efficiency we need to deal with all of these individual components. This article focuses on the last mentioned component the gearbox efficiency.

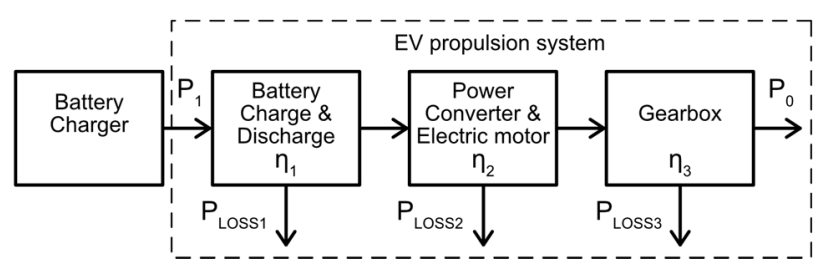

Fig. 1. The individual components of the efficiency of the EV propulsion system [4].

$$
\eta_{E V}=\frac{P_{0}}{P_{1}}=\frac{P_{0}}{P_{0}+\sum_{i=1}^{3} P_{L O S S i}}=\eta_{1} \eta_{2} \eta_{3}
$$

Overall gearbox efficiency is determined by individual components loss or equivalently the power losses of the individual components of the powertrain: gearing losses, bearing losses, sealing losses, synchronizing losses, clutch losses, torque converter losses, auxiliary units [5]. Gear power losses are strongly related to lubrication. Load dependent losses are caused by the frictional effects in the lubricant film and load independent losses are from squeezing, churning and windage effects [6]. These hydraulic losses are well analysed in [6].

In scientific publications certain values of gearbox efficiency are often assumed. These values are often based on calculations and simulations and then they are used for other calculations. For example, in book [4] on page 12 are listed values $95-98 \%$. The authors of paper [7] work with values 86-94\% during the load values $5 \mathrm{Nm}$. Tehrani in his thesis [8] works with gearbox efficiency values above $98 \%$ in some areas of speed and load.

At the Technical University of Liberec current development is focused on a Dual Motor Drive System (DMDS) electric propulsion system shown in Fig. 2. DMDS consists of two electric motors and one singlespeed gearbox with a mechanical differential. Current research shows that this system can provide high drive efficiency under all loads, without limiting the driving dynamics [9]. All components of the propulsion system we test in our lightweight battery electric vehicle for educational purposes, which has a completely open frame from aluminium profiles. This solution gives an excellent access to all parts of the vehicle and allows easy modification [10].

\footnotetext{
Corresponding author: josef.brousek@tul.cz
} 


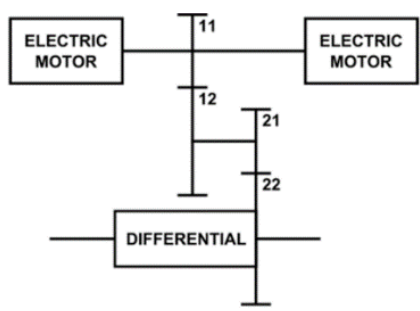

Fig. 2. Dual Motor Drive System components arrangement.

For our next steps in the research, we need to consider the exact values of each component of the overall efficiency. The main aim of our experiment was to measure the efficiency of an EV gearbox in our powertrain testbed.

\section{Methods and Materials}

\subsection{Prototype DMDS gearbox}

The subject of measurement was our prototype DMDS gearbox (shown in Fig. 3) which we designed and made for the purposes of our DMDS research. This prototype gearbox allows for the connection of any two electric motors with a standardized flange NEMA C-face with the limitations of overall maximum input torque at $200 \mathrm{Nm}$ and maximum input speed of $7000 \mathrm{rpm}$. The overall ratio is 5,857 .

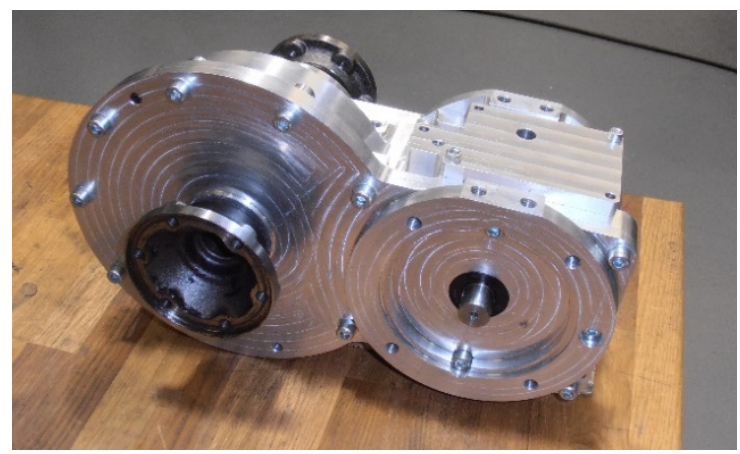

Fig. 3. Prototype DMDS gearbox used for the experiment.

Each of the motors is placed on one side of the gearbox and the torque of both motors is brought to the first shaft of the gearbox. First gear set and the final drive with differential are all used from the third gear of Skoda MQ200 02T gearbox. All bearings are also used from this gearbox. Internal components are placed in our designed gearbox housing. The material of the housing is aluminium alloy EN AW 7021 [AlZn5,5Mg1,5].

The main aim of the experiment was to get relevant values of the overall efficiency as a function of input speed and torque for our gearbox. We plan to continue to use these values for subsequent simulations and other experiments.

\subsection{Powertrain testbed}

We decided to use a special testing mode of our powertrain testbed (shown in Fig. 4) for this gearbox efficiency experiment. This testbed is mainly designed for complete powertrain testing. It means the assembly of the engine-clutch-gearbox-drive shafts.

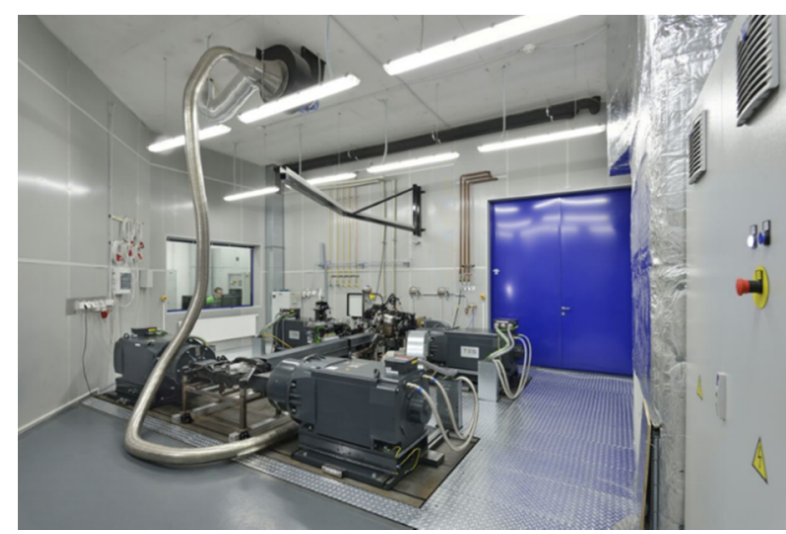

Fig. 4. Powertrain testbed room.

The testbed consists of four asynchronous dynamometers. One pair of dynamometers is composed of Siemens 136 ADG 288WP (each one $120 \mathrm{~kW} \mathrm{/}$ $2600 \mathrm{~min}^{-1} / 440 \mathrm{Nm}$; max. speed $\left.3000 \mathrm{~min}^{-1}\right)$. The second pair is composed of Siemens 111 ADG 286WP (each one $80 \mathrm{~kW} / 2600 \mathrm{~min}^{-1} / 294 \mathrm{Nm}$; max. speed $3000 \mathrm{~min}^{-1}$ ). This solution provides testing of 2 wheel drive and also 4 wheel drive and hybrid powertrain where one axis can be power driven by the combustion engine and the second one by the electric motor shown in Fig. 5. Manual shifting is provided by a shifting robot, which can control the shift lever of manual gearboxes. The testing room is further equipped with the advanced control system, air condition, and extraction of exhaust gases. As fuels, it is possible to use petrol, diesel, LPG, CNG, and hydrogen. We use this testbed mainly for gearbox testing, efficiency measuring and for long-term tests of complete powertrains. During these tests, we normally use combustion engines as propulsion of the testing assembly and the braking torque is generated by a different number of dynamometers as required.
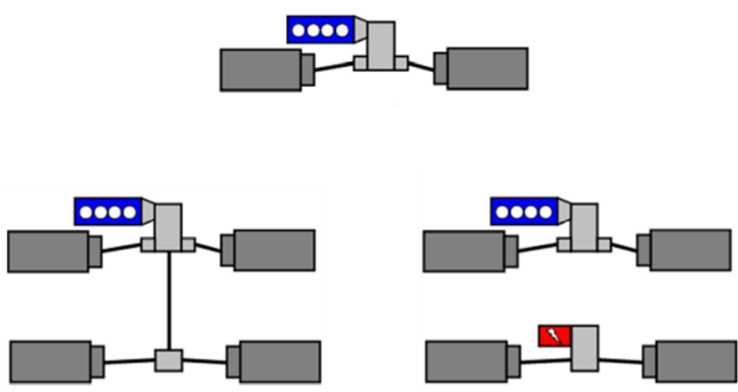

Fig. 5. Powertrain testbed layout possibilities.

\subsection{Experimental setup}

The special mode mentioned in the previous subsection makes it possible to use one dynamometer as a motor and the second one on the other side as a dynamometer as shown in Fig. 6. Each dynamometer is equipped with very precise measurement of speed and torque. Specifically, the torque is measured by torque flange HBP T40B with accuracy class 0,05 . The torque flange is combined with the integrated speed measuring system. 


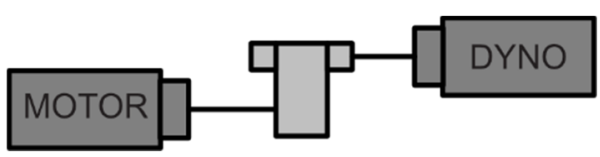

Fig. 6. Powertrain testbed layout for the gearbox efficiency measurement.

The gearbox was placed between two dynamometers on the experimental frame from aluminium profiles at the powertrain testbed shown in Fig. 7. Mounting points were retained as they are used in the vehicle. The gearbox input shaft was connected to the dynamometer which was used in a motor mode. The output shaft was connected to the opposite dynamometer. To evaluate gearbox efficiency we measured and logged values of input speed and torque and the same variables for the output. During testing, we controlled input speed and output torque by the testbed control system.

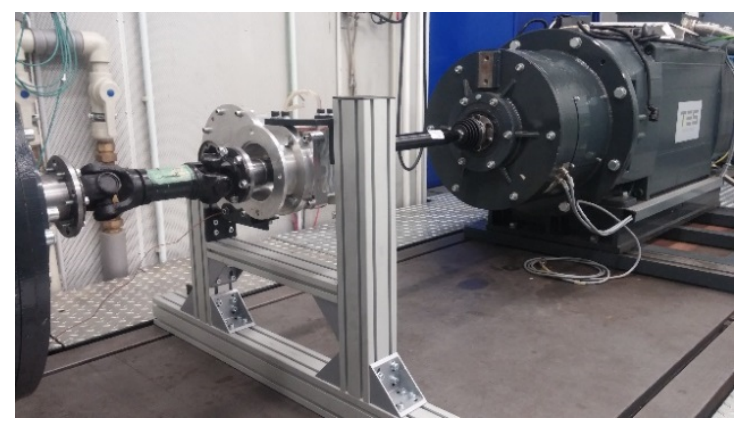

Fig. 7. Experimental setup of the gearbox efficiency measurement.

For the purpose of this experiment, we had to lock the differential, because we could use only one output shaft of the gearbox. Locking was made by using a special element which was put instead of the differential gear (shown in Fig. 8).

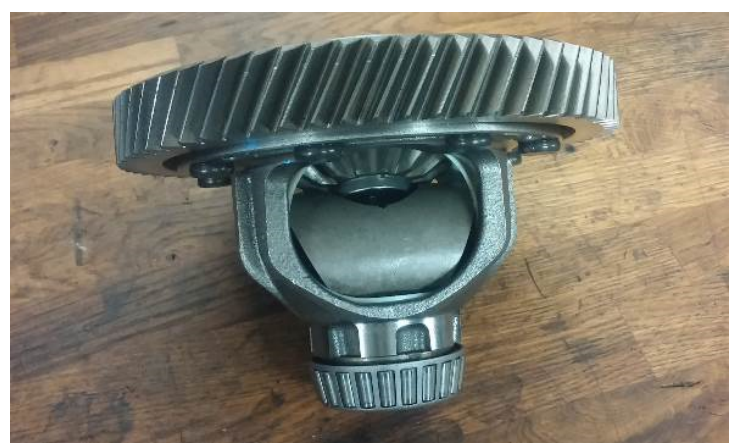

Fig. 8. A special element used to lock the differential

The oil temperature was measured by thermocouple OMEGA Engineering TJC200-CAIN-M025U-150 placed at the inner bottom of the gearbox housing.

\subsection{Experiment details}

As we mentioned in the previous subsection we controlled the values of input speed and output torque. The measurements were performed at the points with the required values shown in Table 1. It was measured for each speed at all loads.
Table 1. Required values for the experiment.

\begin{tabular}{|c|c|c|}
\hline \multicolumn{2}{|c|}{ Controlled } & Calculated \\
\hline Input speed & Output torque & Input torque \\
\hline $\mathrm{rpm}$ & $\mathrm{Nm}$ & $\mathrm{Nm}$ \\
\hline 500 & 117,1 & 20,0 \\
\hline 1000 & 234,3 & 40,0 \\
\hline 1500 & 351,4 & 60,0 \\
\hline 2000 & 468,6 & 80,0 \\
\hline 2500 & 500 & 85,4 \\
\hline 3000 & - & - \\
\hline
\end{tabular}

Note: We couldn't measure in the full range of gearbox input torque (max. $200 \mathrm{Nm}$ ) because we used only one input point of the gearbox which is designed for max. input torque $100 \mathrm{Nm}$. The control system of the powertrain testbed allowed us to use max. output torque $500 \mathrm{Nm}$. That is the reason why the last required value of output torque is $500 \mathrm{Nm}$ and not $585,7 \mathrm{Nm}$, which would correspond to the max. usable input torque $100 \mathrm{Nm}$ for only one input point.

The amount of oil charge was determined on the basis of a $3 \mathrm{D}$ model during the development process of the experimental gearbox. We decided to run two complete efficiency measurements with two different amounts of oil charge to determine the effect of the oil charge on the efficiency. For the first experiment, we filled the gearbox with $500 \mathrm{~g}$ of oil. With this amount of oil charge the oil level reached the bottom part of the final drive gear. For the second experiment, we used $820 \mathrm{~g}$ of oil. In this case the oil level reached the bottom of the gear on the input shaft. The type of used gear oil was Mogul Syntrans 75W90 with the specification API GL-4+ for both measurements. This type of oil is normally used in conventional Skoda MQ200 vehicle gearbox. We used this type of oil mainly because almost all internal components come from this gearbox as we described in subsection 2.1.

Each measured point was measured for $30 \mathrm{~s}$ with the recording frequency of $100 \mathrm{~Hz}$. During the experiment, we logged the following values of input speed $\omega_{\text {in }}$ and torque Min, output speed $\omega_{\text {out }}$ and torque $M_{\text {out }}$ and oil temperature. From the logged values were calculated the mean values for each measured point by Matlab. Then we calculated the input power $P_{\text {in }}$ and output power $P_{\text {out }}$ on the basis of the obtained mean values and calculated the overall gearbox efficiency $\eta_{\text {gearbox }}$ according to the equation (2).

$$
\eta_{\text {gearbox }}=\frac{P_{\text {out }}}{P_{\text {in }}}=\frac{\omega_{\text {out }} M_{\text {out }}}{\omega_{\text {in }} M_{\text {in }}}
$$

\section{Results}

The calculated overall gearbox efficiency from the measurement with $500 \mathrm{~g}$ oil charge is shown in Fig. 9 and with $820 \mathrm{~g}$ oil charge in Fig. 10. Each symbol corresponds to a different input speed of the gearbox. For each input speed can be found a point close to the input torque values $20 \mathrm{Nm}, 40 \mathrm{Nm}, 60 \mathrm{Nm}, 80 \mathrm{Nm}$ and 85,4 Nm.

The resulting values of the overall gearbox efficiency for $820 \mathrm{~g}$ oil charge in Fig. 10 are lower at every point than the other results for $500 \mathrm{~g}$ oil charge. 


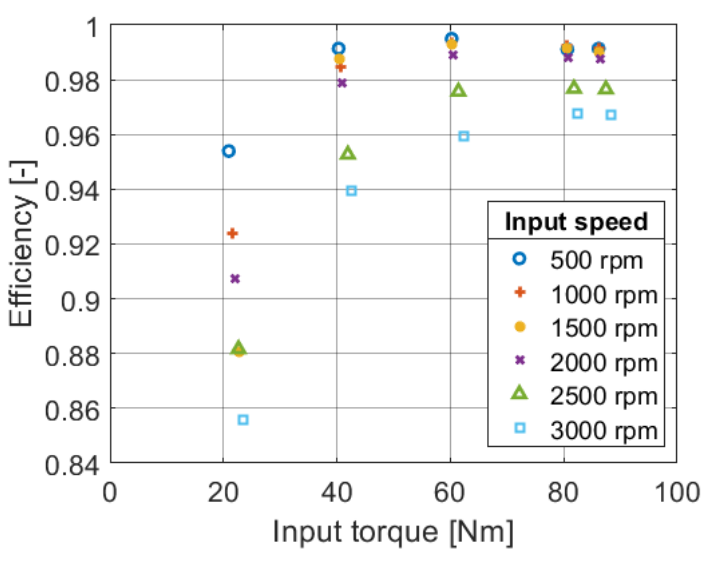

Fig. 9. Results of the overall gearbox efficiency for $500 \mathrm{~g}$ oil charge.

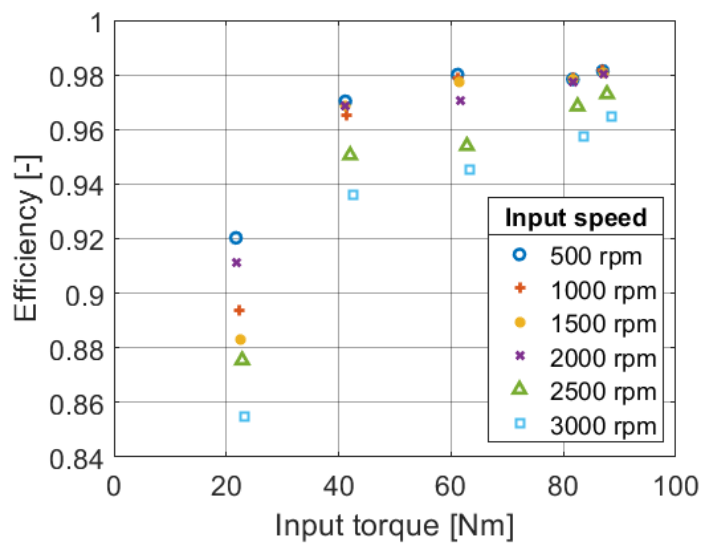

Fig. 10. Results of the overall gearbox efficiency for $820 \mathrm{~g}$ oil charge.

We used the obtained resulting values from both previous graphs to build efficiency maps in Matlab shown in Fig. 11 and Fig. 12. Mesh grids for both maps were created by the linearization with 30 evenly spaced points between the minimal values and maximal values of the input speeds and input torques.

The oil temperature values measured at the inner bottom of the gearbox housing were during the measurement with $820 \mathrm{~g}$ oil charge in the range $40,3-51,2^{\circ} \mathrm{C}$ with average value of $44,5^{\circ} \mathrm{C}$ and with $500 \mathrm{~g}$ oil charge in the range $38,1-51,2^{\circ} \mathrm{C}$ with average value of $44,0{ }^{\circ} \mathrm{C}$.

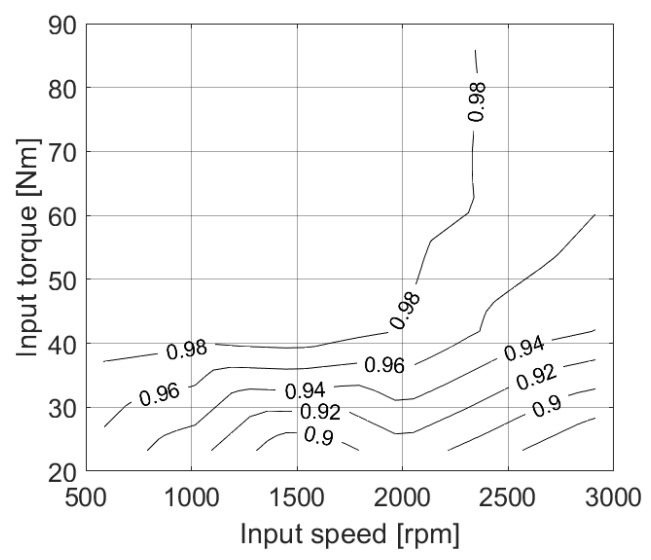

Fig. 11. Overall gearbox efficiency map for $500 \mathrm{~g}$ oil charge.

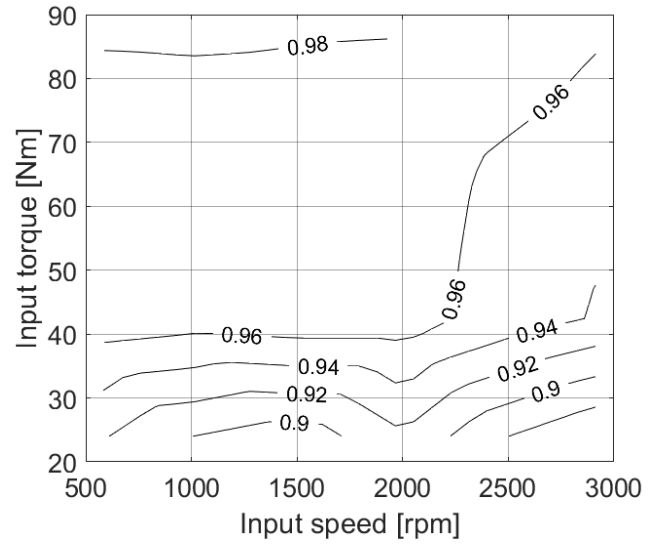

Fig. 12. Overall gearbox efficiency map for $820 \mathrm{~g}$ oil charge.

\section{Discussion}

The results of the experiment provided detailed data on the efficiency of our prototype DMDS gearbox depending on the input speed and the input torque in the range of input speed of 500-3000 rpm and in the range of input torque of $20-85,4 \mathrm{Nm}$.

In the introduction section of the paper, we mentioned some efficiency values stated in books and other scientific articles. There we can find values of gearbox efficiency around $86 \%$ to more than $98 \%$. A lot of them are based on calculations and simulations. The resulting values of our experiment with our prototype DMDS gearbox are almost in the same range. Values for $500 \mathrm{~g}$ oil charge at input speeds of $500 \mathrm{rpm}, 1000 \mathrm{rpm}$ and $1500 \mathrm{rpm}$ in some areas of input torque of $40 \mathrm{Nm}, 60 \mathrm{Nm}, 80 \mathrm{Nm}, 86 \mathrm{Nm}$ are even higher than $99 \%$. On the other hand, in the areas of the whole measured input speeds of 500-3000 rpm and at a low load of around $20 \mathrm{Nm}$, the values are significantly lower - in the range of $85,6-95,4 \%$.

A lot of the inside components of the gearbox come from Skoda MQ200 02T gearbox commonly used in today's vehicles. The results of our experiment may also indicate efficiency values in some conventional vehicle transmissions.

The experiment was performed with two different amounts of oil charge. The results show that the amount of charge in the measured gearbox has a relatively significant effect on its overall efficiency. The resulting values are on average by $1,2 \%$ lower with the oil filling $820 \mathrm{~g}$ than with $500 \mathrm{~g}$. The maximum difference is $3,4 \%$ at the point $500 \mathrm{rpm}$ of input speed and $21 \mathrm{Nm}$ of input torque. We plan to investigate more precisely the choice of oil type and its right amount in the next steps to improve the efficiency of our prototype DMDS gearbox.

In our opinion, the results from our experimental analysis of the overall efficiency of our prototype DMDS gearbox in the powertrain testbed confirmed the quality design and the technological process of its production. The resulting overall gearbox efficiency maps can be used for detailed advanced simulations of new EV propulsion systems because they are built from efficiency values measured in specific values of input speed and input torque. 
For further work on analyzing the efficiency of this gearbox it would be appropriate to analyze the efficiency in the rest of input torque range $100 \mathrm{Nm}$ to $200 \mathrm{Nm}$ and in the rest of input speed range $3000 \mathrm{rpm}$ to $7000 \mathrm{rpm}$. For such measurement it would be necessary to use another special testbed with required parameters. Using the resulting efficiency values it certainly would be interesting to measure the efficiency in the smaller intervals of input speed and input torque in the areas of lower input torque than $40 \mathrm{Nm}$. This would allow us to build more accurate efficiency maps in these areas where there are significant changes in efficiency values. Also it would be appropriate to select such controlled output torque values so that the input torque values would be closer to decimal values. Further work could also be done on efficiency analysis at higher oil temperature values.

This publication was written at the Technical University of Liberec as part of project 21127 with the support of the Specific University Research Grant, as provided by the Ministry of Education, Youth and Sports of the Czech Republic in the year 2018.

\section{References}

1. T. Gechev, M. Mruzek, D. Barta, Comparison of real driving cycles and consumed braking power in suburban Slovakian driving, MATEC Web of Conferences - BulTrans 2017, 133 (2017)

2. C. Chan, The state of the art of electric, hybrid, and fuel cell vehicles, Proceedings of the IEEE, 95, 704718 (2007)

3. K. Rajashekara, Present status and future trends in electric vehicle propulsion technologies, IEEE Journal of Emerging and Selected Topics in Power Electronics, 1, 3-10 (2013)

4. I. Husain, Electric and hybrid vehicles design fundamentals (CRC Press, Florida, 2003)

5. H. Naunheimer, B. Bertsche, J. Ryborz, W. Novak, Automotive transmissions, (Springer-Verlag Berlin Heidelberg, Berlin, 2011)

6. C. Gorla, F. Concli, K. Stahl, B. Höhn, K. Michaelis, H. Schultheiß, J. Stemplinger, Hydraulic losses of a gearbox: CFD analysis and experiments, Tribology International, 66, 337-344 (2013)

7. J. Li, C. Li, J. Huang, Transmission efficiency analysis and experiment research of gear box, Advances in Engineering Research (AER), 105, 298-303 (2017)

8. M. Tehrani, Energy efficiency consideration in electric vehicle transmissions. Lappeenranta University of Technology, (2013) https://www.doria.fi/bitstream/handle/10024/90781/F inal\%20thesis\%20last $\% 20$ revision\%20END.pdf?seq uence $=2$ (April 23, 2018)

9. P. Jandura, J. Břoušek, M. Bukvic, The concept of a highly efficient powertrain for an electric vehicle with respect to vehicle driving dynamics. International Conference on Electrical Drives and Power Electronics, Tatranska Lomnica, Slovakia, 422-429 (2015)
10. P. Jandura, M. Bukvic, Lightweight battery electric vehicle for educational purposes, Applied Mechanics and Materials, 390, 281-285 (2013) 